\title{
滿洲崖玄米のビタミン $B_{1}$ 含有量に就て
}

\author{
川上行藏, 青水… 郎 \\ (大陸 科 學 院) \\ 昭和 18 年 6 月 9 日受理
}

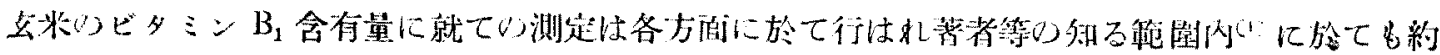

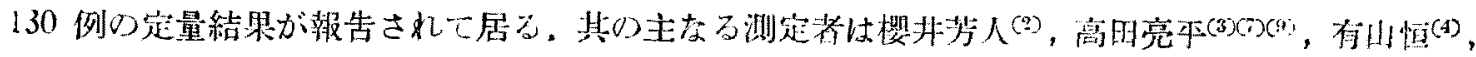

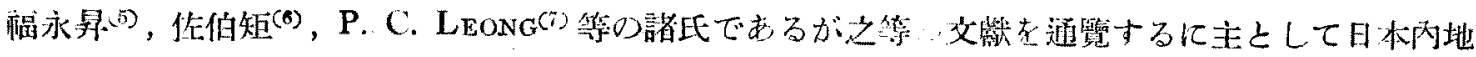

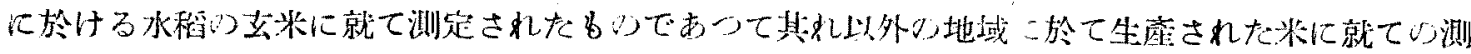

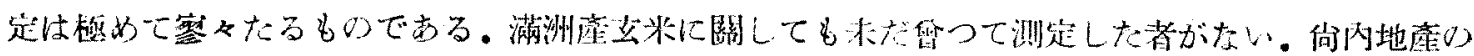

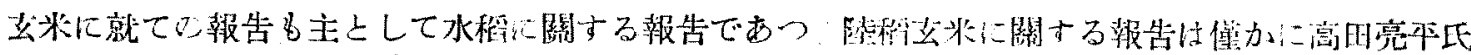

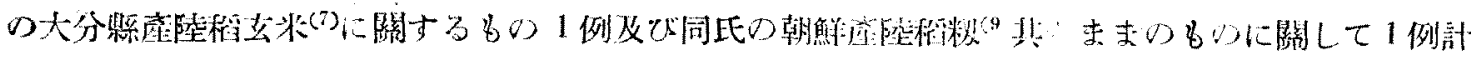

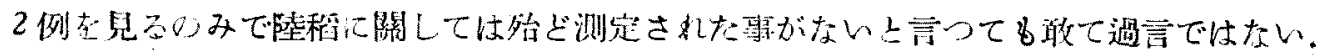

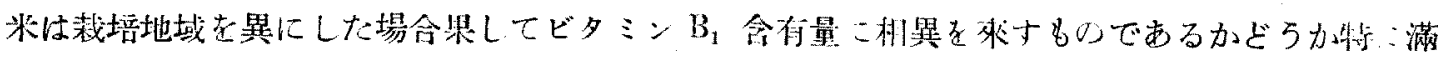

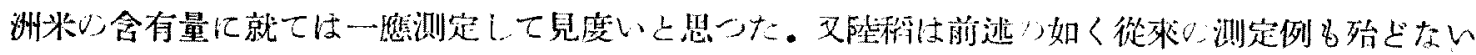

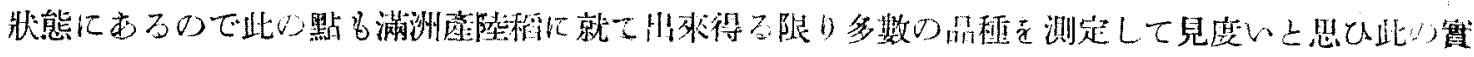

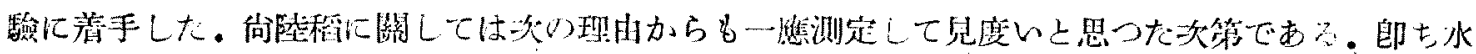

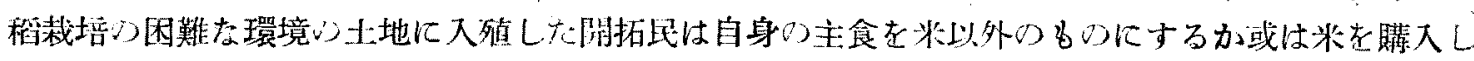

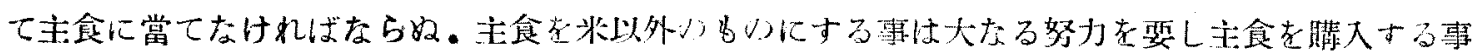

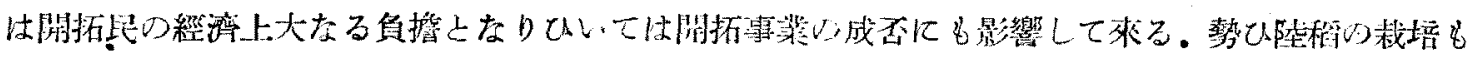

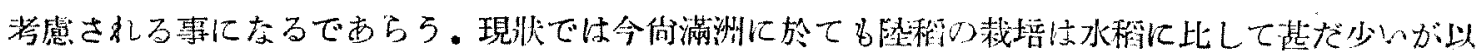

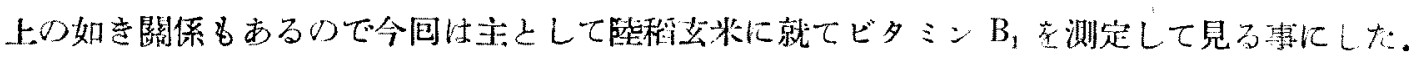

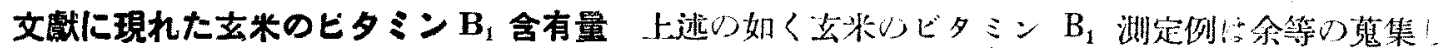

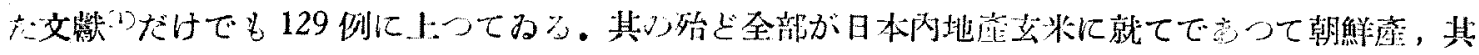

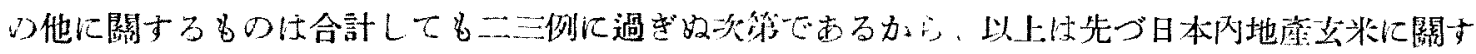

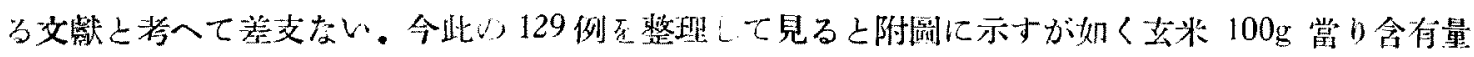

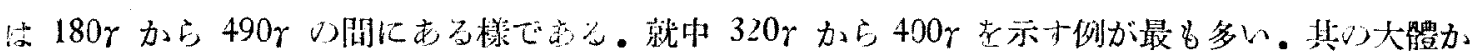

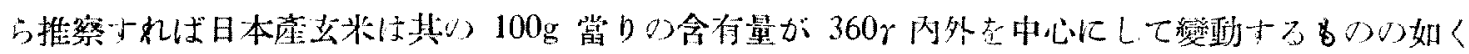

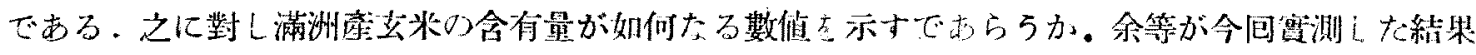
は坎つ如くである。

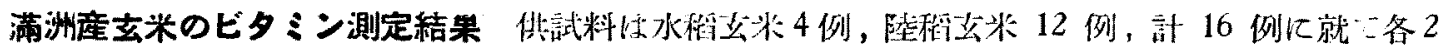

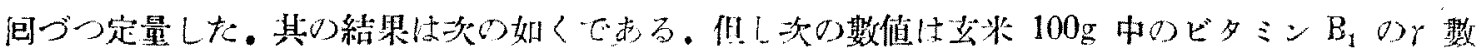

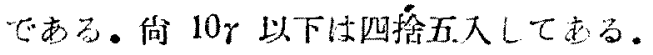

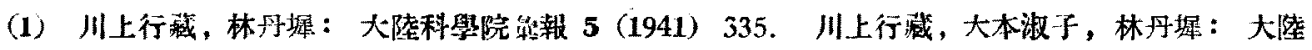

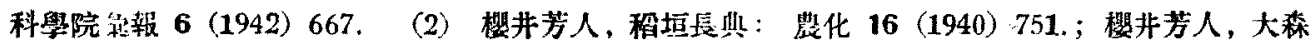

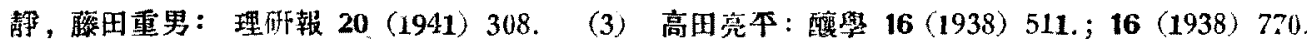

（4）有山恒，星跨龍策，中濢義四郎：農化 17 (1941) 25 . (5) 福永昇：國民街生 16 (1939)

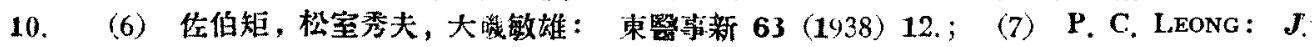
Malaycs Lrauch Lirit. Med. Issoc., 4 (1941) 308. (8) 高明亮本： 釀學， 19 (1941) 134. ,

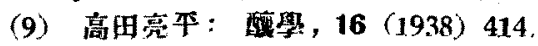




\begin{tabular}{|c|c|c|c|c|c|c|}
\hline $390 \mathrm{rbL}$ & 0 例 & $330 r 2$ 例 & 250 ○ 4 例 & $210 \mathrm{r} 1$ 例 & $160 r \perp$ 例 & $k_{0} r 1$ 件 \\
\hline $38 n^{\prime \prime}$ & 1 例 & $320 "$ " 例 & $240^{\prime \prime} 1$ 例 & $190^{\prime \prime} 2$ 例 & $140 " 1 x$ 例 & \\
\hline $360^{\prime \prime}$ & I 例 & $310^{\prime \prime} 3$ 例 & $230 " 1$ 例 & $180 " 2$ 例 & $120^{\prime \prime} 1$ 例 & \\
\hline $340^{\prime \prime}$ & 2 例 & $260 "$ " 3 例 & $220^{\prime \prime} 1$ 例 & $170^{\prime \prime} 1$ 例 & $90^{\prime \prime} 1$. 例 & \\
\hline
\end{tabular}

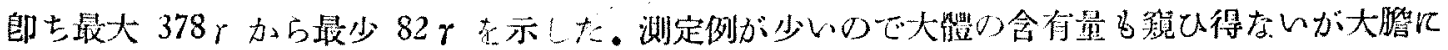

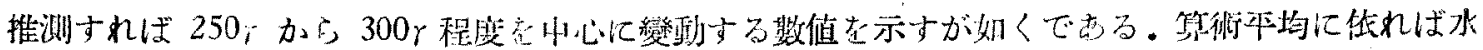

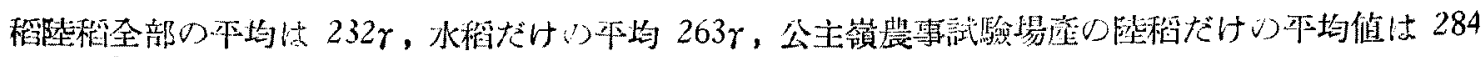

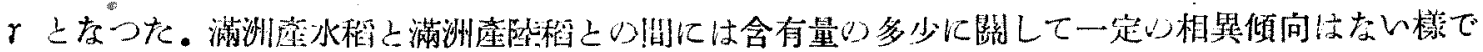

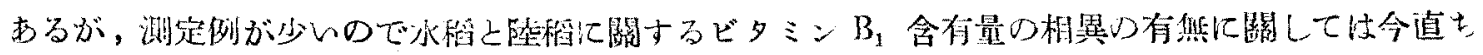

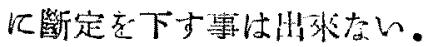

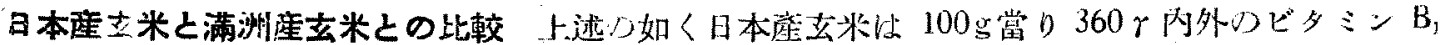

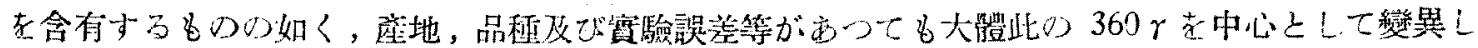

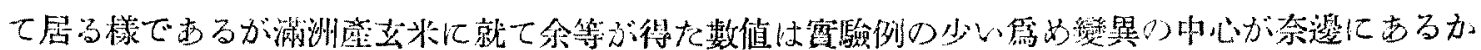

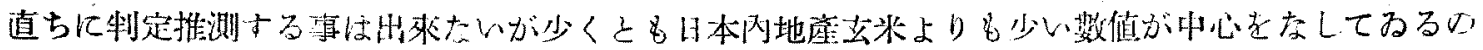

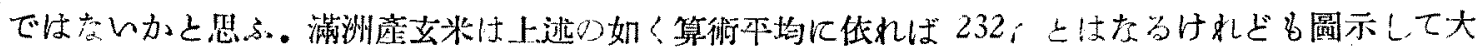

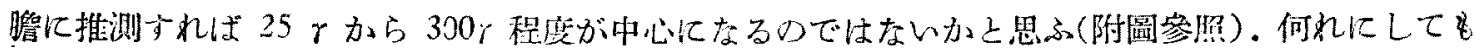

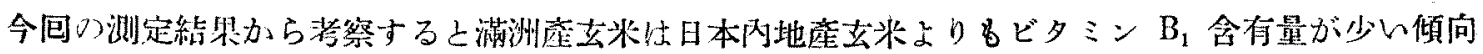

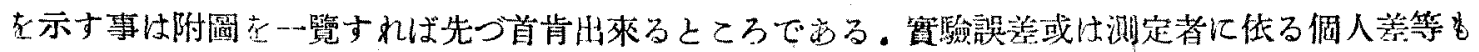

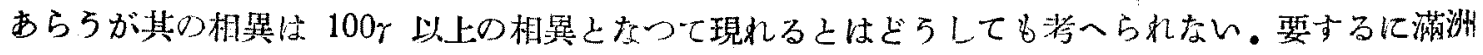

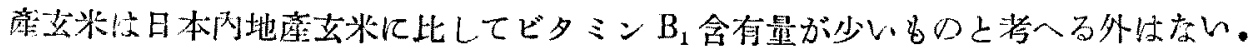

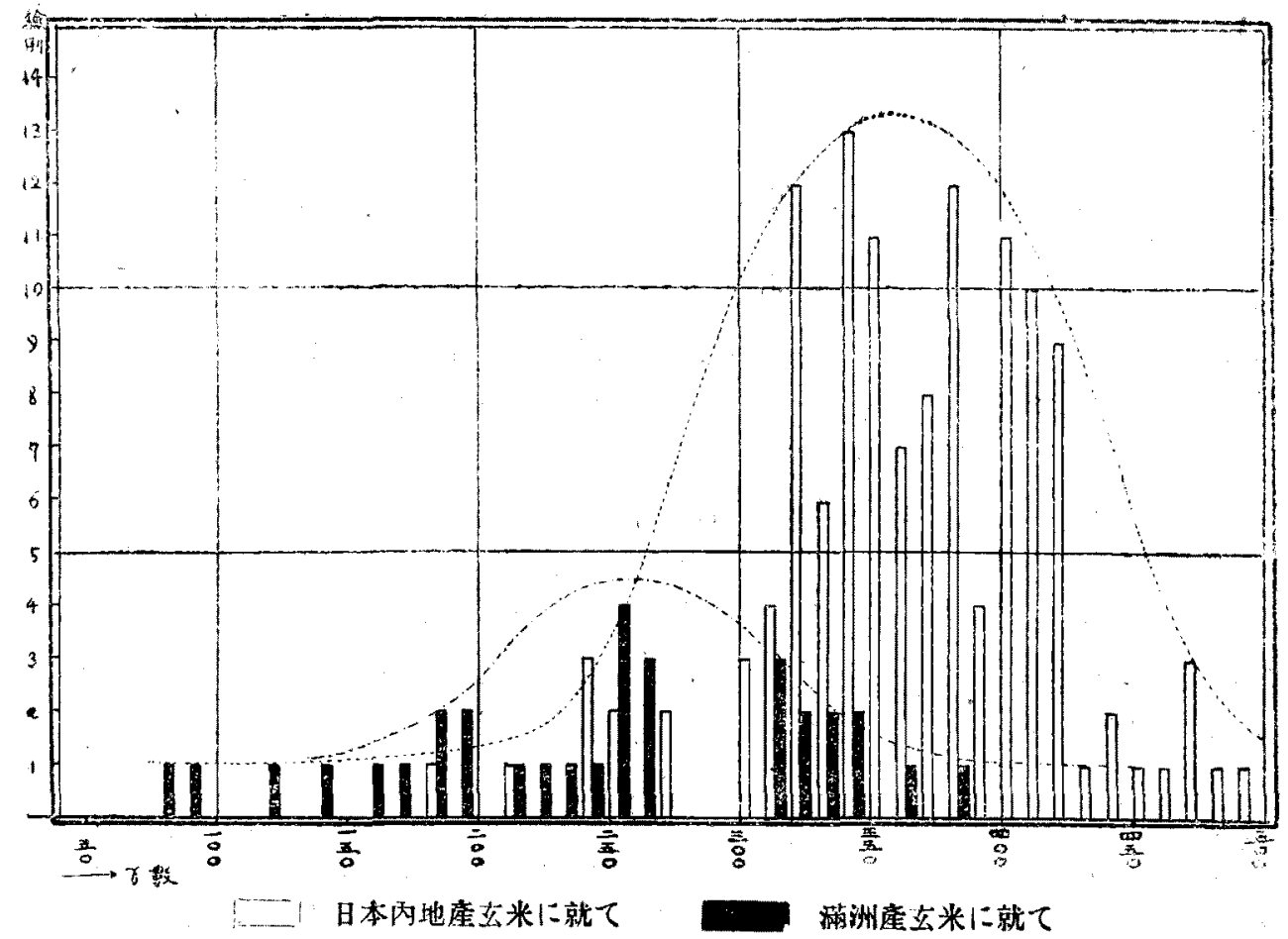

霂洲産玄米のビタン $\mathbf{B}_{1}$ 含有率の低き理由に就ての考察 以上の如く余等の测定した結果から

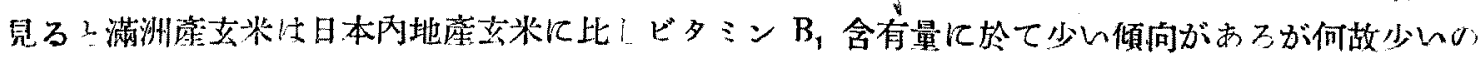




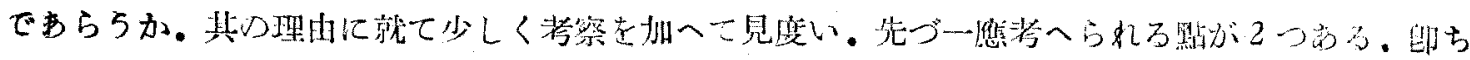

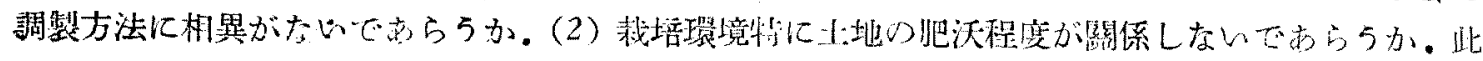
D 2 つ點でする。

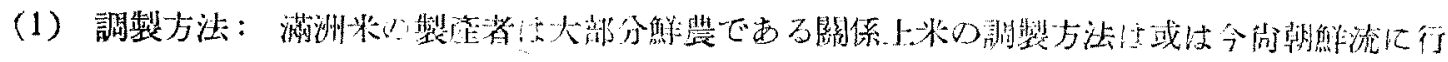

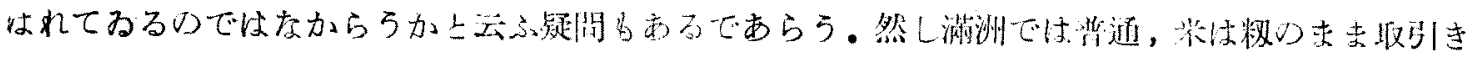

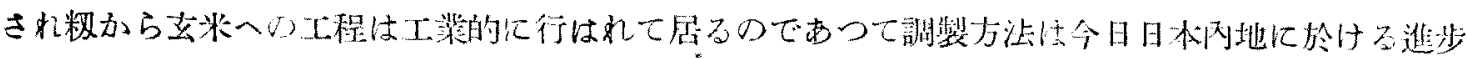

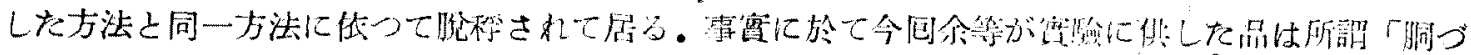

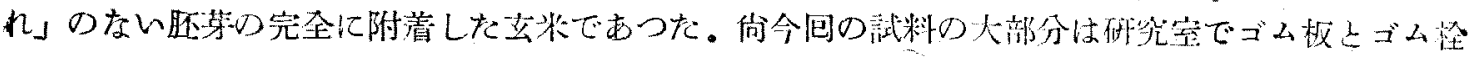

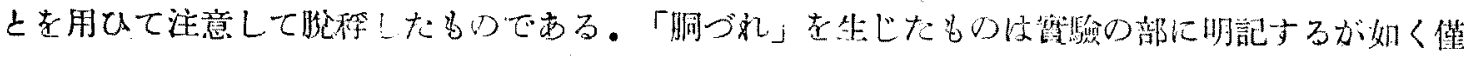

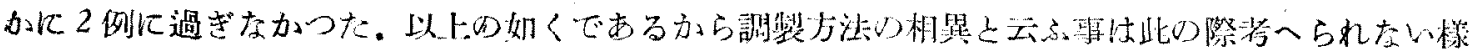
石了。

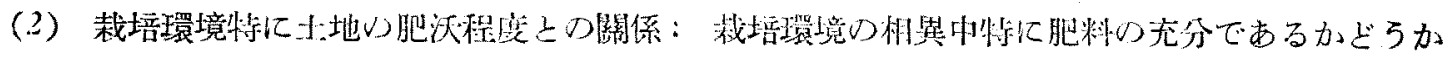

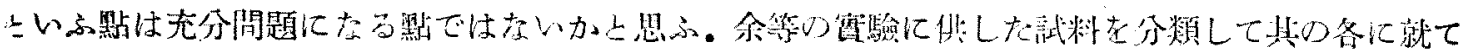

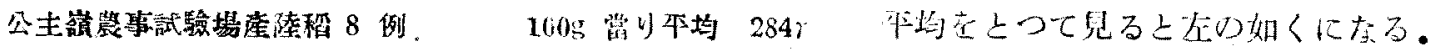

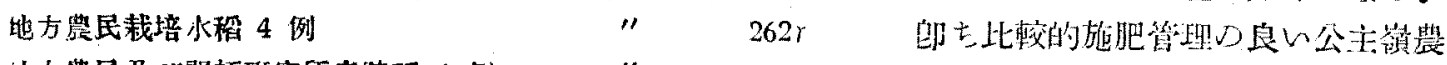

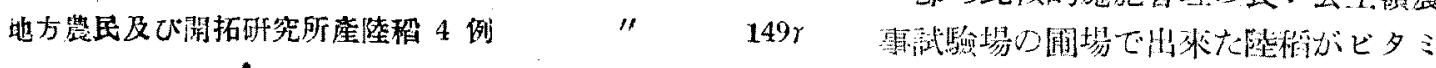

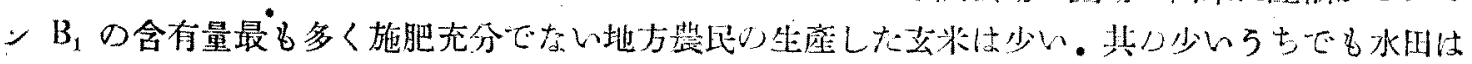

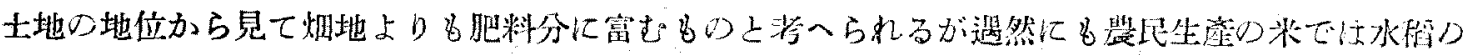

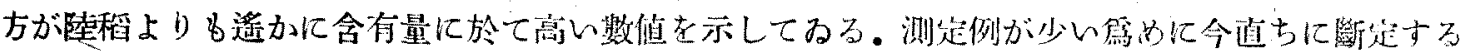

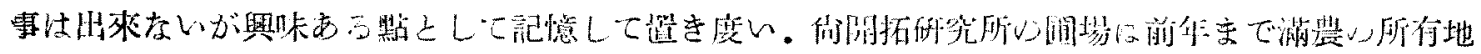

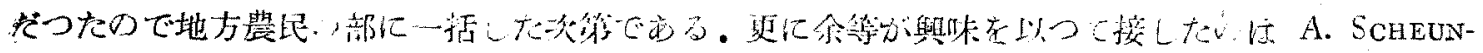

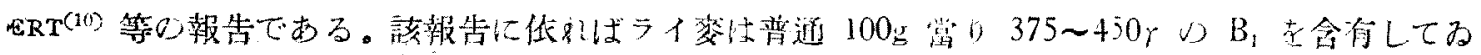

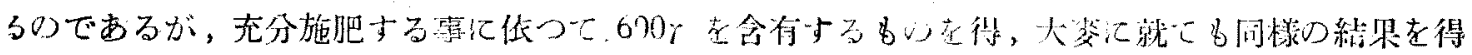

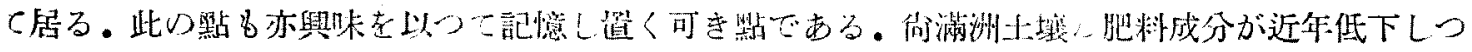

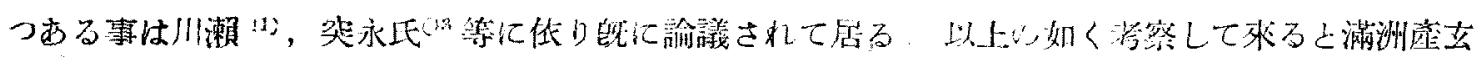

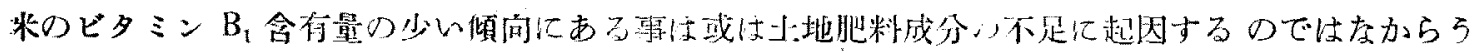
加思家。

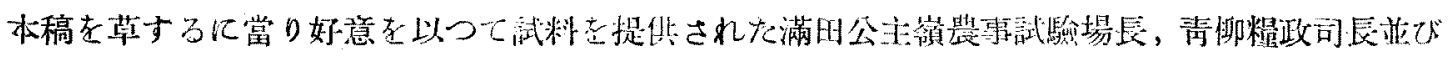

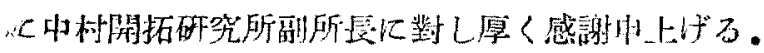

\section{聲 驗の部}

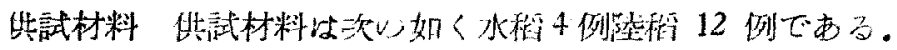

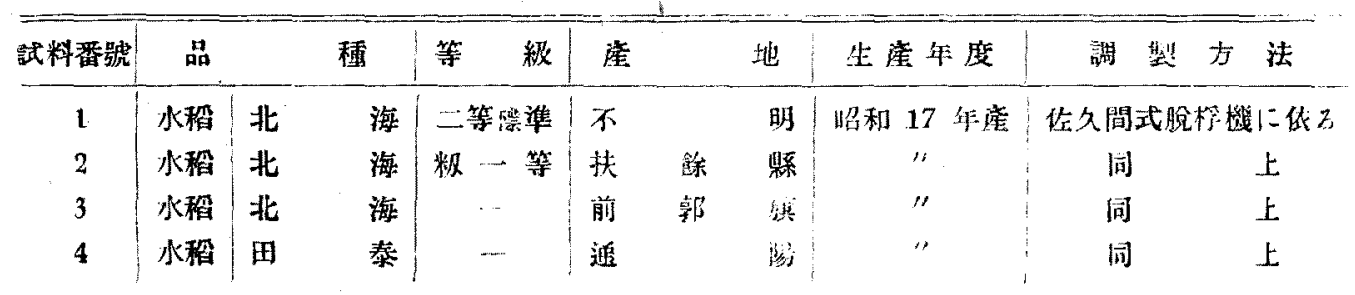

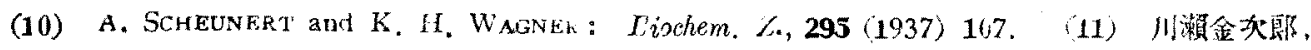

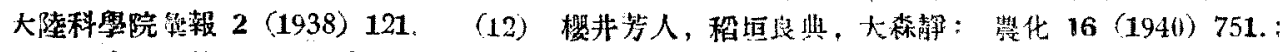

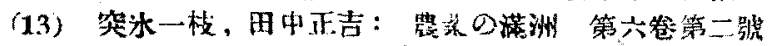




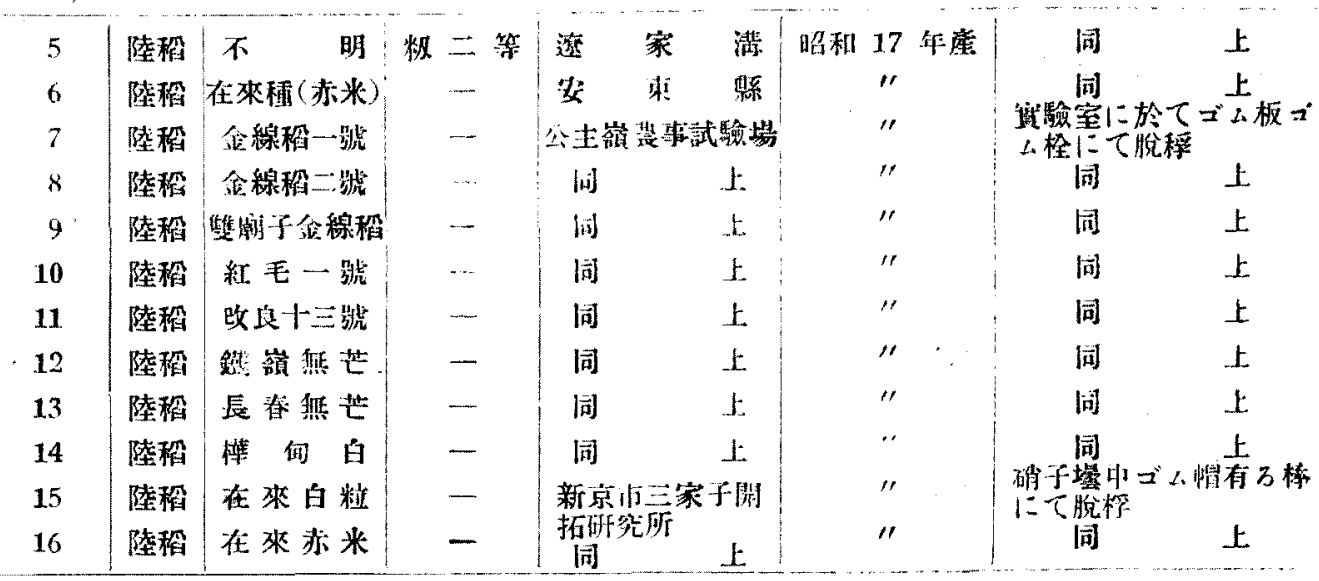

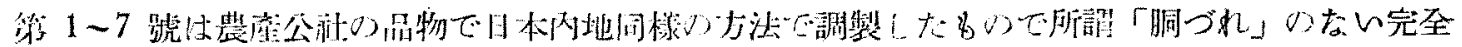
存玄修である。

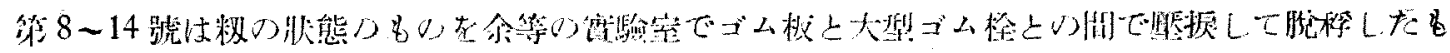
ので完全度者米である。

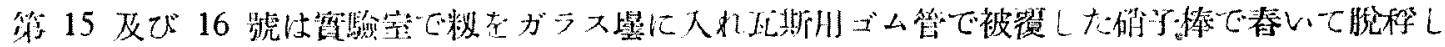

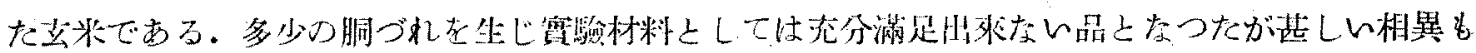

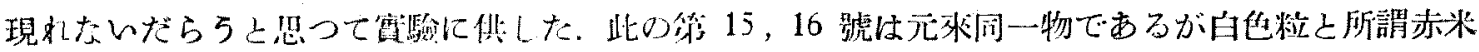

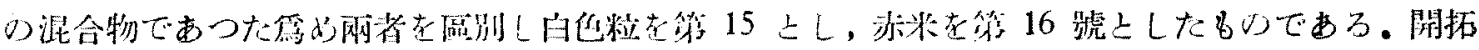

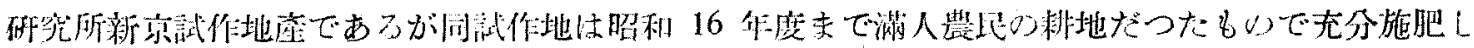
てない主地に䍜したものである。

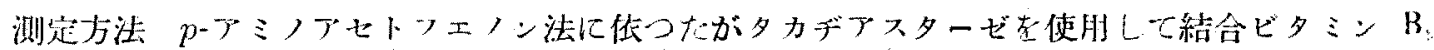

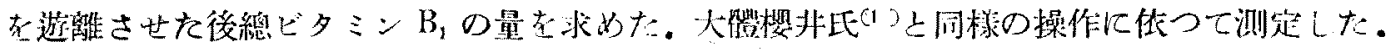

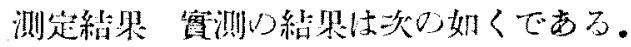

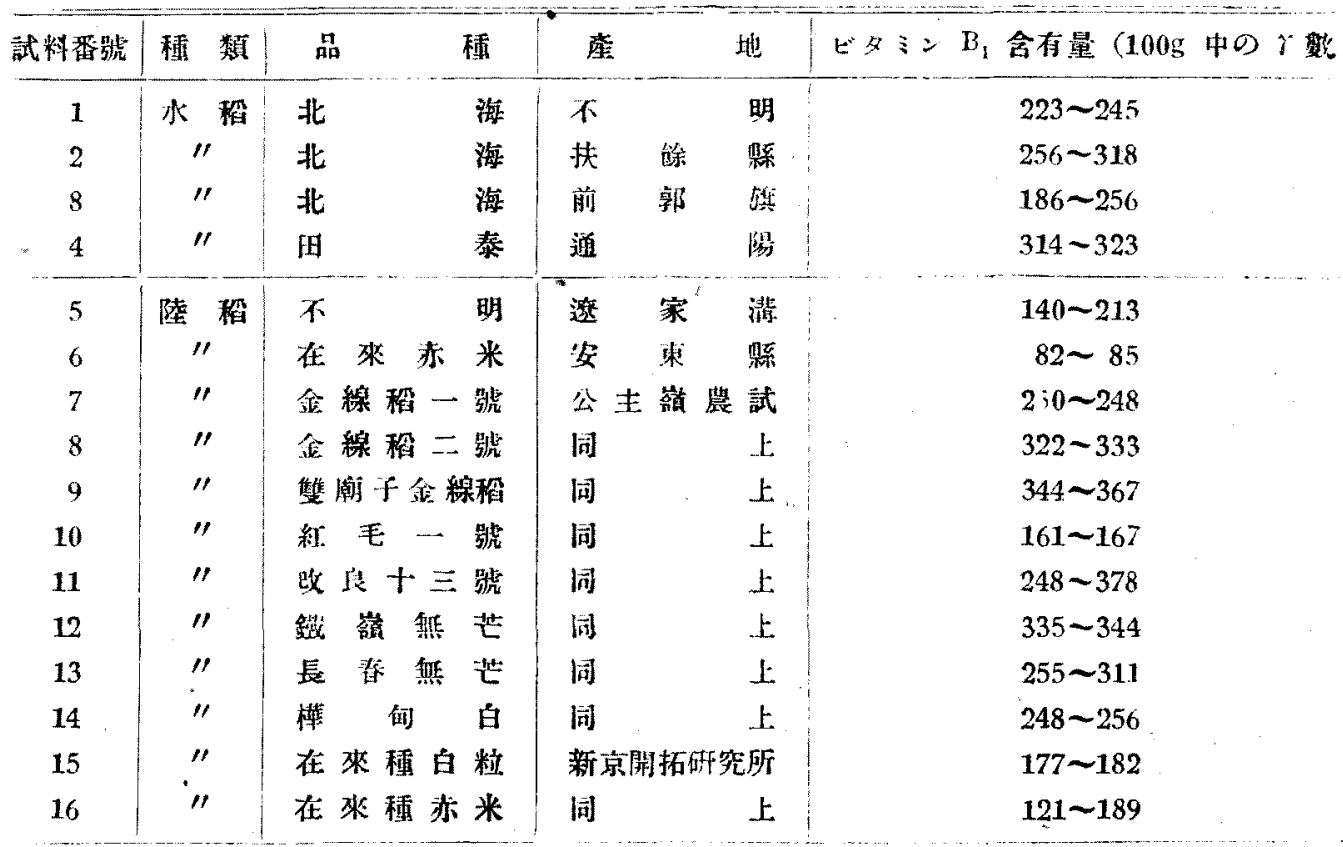

